\title{
Laboratory Tests in Assessing the Bleeding Risk in Patients Receiving Direct Oral Anticoagulants (DOACs)
}

\author{
Subhash Edupuganti, Mary Wyrzykowski, Elizabeth Wey, Ming Xie* \\ Department of Pathology, Oakland University School of Medicine, William Beaumont Hospital, Troy, USA \\ Email: *ming.xie@beaumont.org
}

How to cite this paper: Edupuganti, S., Wyrzykowski, M., Wey, E. and Xie, M. (2018) Laboratory Tests in Assessing the Bleeding Risk in Patients Receiving Direct Oral Anticoagulants (DOACs). World Journal of Cardiovascular Diseases, 8, 257-264. https://doi.org/10.4236/wjcd.2018.85025

Received: April 18, 2018

Accepted: May 25, 2018

Published: May 28, 2018

Copyright ( 92018 by authors and Scientific Research Publishing Inc. This work is licensed under the Creative Commons Attribution International License (CC BY 4.0).

http://creativecommons.org/licenses/by/4.0/

\begin{abstract}
Direct oral anticoagulants (DOACs) - apixaban, rivaroxaban and dabigatran have become the first line medications for patients with thromboembolism. However, DOAC therapy-associated bleeding complications remain the major clinical concern for these patients. This study compared laboratory test results from 82 patients with and 361 patients without DOAC-associated bleeding with the goal of determining the value of laboratory tests in assessing bleeding risk in these patients. There was no age or gender difference between patients with and without DOAC therapy-associated bleeding complications. Both prothrombin time (PT) and partial thromboplastin time (PTT) prolonged at the same time showed good correlation with bleeding complications for patients receiving dabigatran (91.7\%) and rivaroxaban (41.2\%). When comparing patients with bleeding and those without bleeding complications, impaired renal function showed high correlation $(\mathrm{p}<0.01)$, impaired liver function showed moderate correlation $(p=0.03)$, and thrombocytopenia showed no correlation ( $\mathrm{p}>0.05)$ among patients with bleeding complications. A small population of patients had never experienced bleeding complications, despite the laboratory test results being similar to patients who suffered from bleeding complications. Laboratory tests may be useful in the assessment and prediction of bleeding complications in patients receiving DOAC therapy. However, it is important to incorporate both laboratory findings with the clinical information, such as concomitant antithrombotic agents and other underlying diseases in the decision making of DOAC therapy in order to reduce therapy-related bleeding risk.
\end{abstract}

\section{Keywords}

Direct Oral Anticoagulants, Prothrombin Time, Partial Thromboplastin Time, Apixaban, Rivaroxaban, Dabigatran, Bleeding Complications 


\section{Introduction}

Apixaban, rivaroxaban and dabigatran are direct oral anticoagulants (DOACs), which are often indicated for the prevention of stroke caused by atrial fibrillation and the management of venous thromboembolism [1] [2] [3]. Dabigatran is a direct thrombin inhibitor, while apixaban and rivaroxaban are both direct factor Xa inhibitors [4] [5]. DOACs have gained wide use recently as alternatives to the traditional oralvitamin $\mathrm{K}$ antagonists (warfarin) therapy [6] [7]. However, the therapeutic benefit is not without risk of bleeding complications, such as hematuria and gastrointestinal bleeding [8] [9].

Anticoagulation therapy should be individualized based on both benefits and risks associated with this therapy [10] [11]. Concomitant antithrombotic agents, patient's age and impaired liver and renal functions are amongst the risk factors associated with an increased bleeding complications in these patients [12] [13]. Multiple clinical trials on DOAC therapy have revealed valuable information on the risk factors of therapy-associated bleeding complications [14] [15] [16]; however, there are still limited studies on the risk factors of bleeding in the post-marketing general practice, especially on the roles of laboratory tests to determine the bleeding risk in patients receiving DOAC therapy. Insufficient laboratory evaluation before and/or during therapy may increase the risk of therapy-induced bleeding complications among certain patients. This study reviews the value of laboratory tests in assessing the bleeding risk in patients on DOAC therapy.

\section{Materials and Methods}

\subsection{Patient Population}

Using existing clinical laboratory data, patients with prolonged partial thromboplastin time (PTT) were selected at William Beaumont hospital, Troy, Michigan from August 2015 to April 2016. Among them, 443 patients were identified as receiving DOAC therapy during the same time period, including 82 patients with documented bleeding episodes and 361 patients without any bleeding episodes. The electronic medical charts from these patients were retrospectively reviewed. Bleeding complications and concurrent laboratory test results were collected, analyzed and compared amongst the two groups.

Patient population for this study consisted mainly of local residents in the suburban region of a major US metropolitan city. A pilot study was performed initially to determine the number of patients, laboratory tests and clinical information to be included in this study in order to perform meaningful statistical analysis. Patients younger than 19 years and older than 90 years were excluded.

\subsection{DOAC Therapy Information}

The clinical indications and dosing regimen of DOAC therapy were based on the clinically established as well as United States Food and Drug Administration (FDA) approved guidelines [17] [18]. The clinical indications for DOAC therapy 
include atrial fibrillation, deep vein thrombosis and pulmonary embolism. Patients received one of the following: apixaban $2.5 \mathrm{mg}$ or $5.0 \mathrm{mg}$ bid; dabigatran $75 \mathrm{mg}$ or $150 \mathrm{mg}$ bid; or rivaroxaban $15 \mathrm{mg}$ or $20 \mathrm{mg}$ once daily. No patient received more than one DOAC medications concurrently.

\subsection{DOAC Therapy-Associated Bleeding Complications}

The electronic medical charts of patients with DOAC therapy-associated bleeding complications were reviewed. Some patients had bleeding with multiple organ system involvement; in which case, we recorded the total number of patients with bleeding as opposed to the total number of bleeding episodes.

\subsection{Concurrent Laboratory Test Results}

Laboratory test results from all patients receiving DOAC therapy were reviewed with a focus on platelet count (reference range: 150 - $400 \mathrm{bil} / \mathrm{L}$ ), prothrombin time (9.3 - 12.4 seconds), PTT (23.0 - 30.0 seconds), renal function tests: creatinine $(0.60-1.40 \mathrm{mg} / \mathrm{dL})$ and blood urea nitrogen $(8-22 \mathrm{mg} / \mathrm{dL})$ and liver function tests: aspartate aminotransferase $(10-37 \mathrm{U} / \mathrm{L})$, alanine aminotransferase (8 - $37 \mathrm{U} / \mathrm{L})$, and alkaline phosphatase $(30-110 \mathrm{U} / \mathrm{L})$. Abnormal test results were defined by values outside of the reference ranges set by the Beaumont Hospital laboratory. Abnormal renal and liver function test results were interpreted in the context of data trend analysis in order to assess the likelihood of significant organ dysfunction.

\subsubsection{Laboratory Test Results in Patients with Bleeding Complications} The concurrent laboratory test results in patients at the time of bleeding complications while receiving DOAC therapy were collected and reviewed. All bleeding incidences documented in the electronic medical charts were recorded, including gastrointestinal bleeding, hematuria, epistaxis, bruises, and hematomas. These were discussed in our previous study on DOAC agents [9].

\subsubsection{Comparison between Patients with and without Bleeding Complications}

While receiving DOAC therapy, the laboratory test results between patients with and without bleeding complications were compared and analyzed. Then, the laboratory test results were further compared and analyzed among patients receiving different DOAC agents.

\subsubsection{Laboratory Test Results in Patients without Bleeding Complications}

Of those patients who experienced no bleeding complications during DOAC therapy, some of them had significantly abnormal laboratory test results. These patients were further evaluated with clinical correlations and their laboratory test results were compared with patients who had bleeding complications.

\subsection{Statistical Analysis}

Student's $\mathrm{T}$ test was used for the calculation of $\mathrm{p}$ value to determine the signi- 
ficance of the difference between different patient groups.

\section{Results}

\subsection{General Patient Information and DOAC Therapy-Associated Bleeding Complications}

There were 443 patients included in this study, 228 males and 215 females, with the age range between 20 and 90 years old. The overall incidence of bleeding complications associated with DOAC therapy was $18.5 \%(82 / 443)$ in this patient population. The age and gender distribution was similar between patients with and without DOAC therapy-associated bleeding complications (Table 1). The bleeding incidence in patients receiving apixaban was $10.8 \%$ (19/175), significantly lower $(\mathrm{p}<0.01)$ than patients on rivaroxaban and dabigatran, $22.7 \%$ $(51 / 225)$ and $27.9 \%(12 / 43)$ respectively. Additional analysis on the incidence of bleeding complications, comparison with different DOAC agents, related clinical information and follow-ups were published in our previous study [9].

\subsection{Laboratory Test Results in Patients with DOAC Therapy-Associated Bleeding Complications}

Both prothrombin time (PT) and PTT prolonged at the same time had an overall high association with bleeding incidence (42.7\%), especially for patients receiving dabigatran (91.7\%) and rivaroxaban (41.2\%); however, this was not seen with apixaban (15.6\%). In patients with bleeding complications, abnormal renal function, liver function and thrombocytopenia were seen in $34.1 \%, 29.3 \%$ and $23.2 \%$ of the patients respectively.

\subsection{Laboratory Test Results between Patients with and without Bleeding Complications (Table 2)}

Overall, patients with DOAC therapy-associated bleeding complications had a

Table 1. Gender and age distribution in patients receiving DOAC therapy.

\begin{tabular}{cccccc}
\hline $\begin{array}{c}\text { Bleeding } \\
\text { Complications }\end{array}$ & Total & Males & Females & $\begin{array}{c}\text { Median age } \\
\text { (years) }\end{array}$ & $\begin{array}{c}\text { Range of } \\
\text { age (years) }\end{array}$ \\
\hline Positive & 82 & $42(51.2 \%)$ & $40(48.8 \%)$ & 73 & $26-89$ \\
Negative & 361 & $186(51.5 \%)$ & $175(48.5 \%)$ & 72 & $20-90$ \\
\hline
\end{tabular}

Table 2. Laboratory test results between patients with and without bleeding complications.

\begin{tabular}{cccccc}
\hline $\begin{array}{c}\text { Bleeding } \\
\text { complications }\end{array}$ & & $\begin{array}{c}\text { Both PT/PTT } \\
\text { Prolonged }\end{array}$ & $\begin{array}{c}\text { Abnormal } \\
\text { renal function liver function }\end{array}$ & $\begin{array}{c}\text { Abnormal } \\
\text { Thrombocytopenia }\end{array}$ \\
\hline Positive & Total & $35(42.7 \%)$ & $28(34.1 \%)$ & $24(29.3 \%)$ & $19(23.2 \%)$ \\
Negative & 82 & $62(16.7 \%)$ & $51(14.1 \%)$ & $67(18.6 \%)$ & $69(19.1 \%)$ \\
P value & 361 & $<0.01$ & $<0.01$ & $=0.03$ & $>0.05$ \\
\hline
\end{tabular}


significantly higher incidence of prolonged PT and PTT at the same time ( $\mathrm{p}<$ $0.01)$ as well as impaired renal functions ( $\mathrm{p}<0.01)$, when compared with patients without bleeding. The percentage of impaired liver function was moderately increased in patients with bleeding $(p=0.03)$. There was no significant difference in the incidence of thrombocytopenia between patients with and without bleeding $(\mathrm{p}>0.05)$.

\subsection{Laboratory Test Results in Patients without Bleeding Complications}

In patients without documented bleeding complications while receiving DOAC therapy, a small population (17.5\%) of them was found to have both PT and PTT prolonged at the same time. These patients also had higher incidence of impaired renal and liver functions and thrombocytopenia similar to that observed in patients with bleeding, even though they did not experience bleeding complications during this study period.

The incidence of impaired renal and liver function in patients who never had PT and PTT prolonged at the same time was much lower than in patients who had both prolonged PT and PTT (Table 3).

\section{Discussion}

Bleeding complications remain the major concern for patients receiving DOAC therapy [19] [20]. In our patient population, the overall bleeding incidence was $18.5 \%$ among patients with prolonged PTT while on DOAC therapy. There was no difference in age and gender distribution between patients with and without DOAC therapy-associated bleeding complications in this study. Patients receiving apixaban had a lower bleeding incidence than those on dabigatran or rivaroxaban. Apixaban has been shown to have the benefit of lower bleeding incidence than dabigatran and rivaroxaban in other studies as well [21].

PT and PTT are commonly used coagulation laboratory tests to evaluate the hemostasis status in patients with bleeding disorders [22] [23]. It was common to see prolonged PT and PTT in patients with bleeding complications while receiving DOAC therapy during this study. It was especially interesting that both PT and PTT prolonged at the same time was highly associated with bleeding complications in patients receiving dabigatran or rivaroxaban, but not necessarily with apixaban. Prolonged PT and PTT not only reflect the therapeutic effects of DOACs, but also may indicate a significant underlying coagulopathy, which could be a contributing factor to the bleeding complications in these patients.

Table 3. Laboratory test results in patients without bleeding complications.

\begin{tabular}{ccccc}
\hline $\begin{array}{c}\text { Both PT/PTT } \\
\text { prolonged }\end{array}$ & Total & $\begin{array}{c}\text { Abnormal renal } \\
\text { function }\end{array}$ & $\begin{array}{c}\text { Abnormal liver } \\
\text { function }\end{array}$ & Thrombocytopenia \\
\hline Positive & 63 & $18(28.6 \%)$ & $21(33.3 \%)$ & $13(20.6 \%)$ \\
Negative & 298 & $34(11.4 \%)$ & $44(14.8 \%)$ & $56(18.8 \%)$ \\
\hline
\end{tabular}


Impaired renal function was a significant risk factor in the development of bleeding complications in patients receiving DOAC therapy [24] [25] [26]. When compared with non-bleeding patients in this study, patients with DOAC therapy-associated bleeding complications had a significantly higher incidence of impaired renal function $(\mathrm{p}<0.01)$. Given that all three DOAC medications have a component of renal excretion, abnormal renal function can alter the metabolism of these medications, and thus, increase the bleeding risk. Impaired liver function, to a less extent, had only moderate correlation with bleeding complications ( $\mathrm{p}=0.03)$. Thrombocytopenia, on the other hand, showed no significant difference between patients with and without DOAC therapy-associated bleeding complications.

It was noted in this study that a small population of patients receiving DOAC therapy had both PT and PTT prolonged at the same time, as well as impaired renal and liver functions similar to the bleeding patients, but never experienced bleeding complications during this study period. This suggests that the bleeding complications in patients receiving DOAC therapy have multiple factors involved. Concomitant antithrombotic agents and other underlying diseases, such as peptic ulcer disease and bladder lesions, may also be important in the development of bleeding complications.

Clinical trials provide important information and guidelines in the assessment and management of DOAC therapy-associated bleeding complications. However, patient characteristics studied in clinical trials may differ from that of general patient population and the time frame of clinical trials is typically short. These limitations may underestimate the true bleeding risk [14]. Our study provides some insight into the laboratory evaluation of DOAC therapy-associated bleeding complications among the general patient population. However, the heterogeneity of patients in general practice makes it very challenging, if not impossible, to have complete clinical and laboratory information from these patients. Long-term clinical follow up, adequate laboratory testing, well documented medical conditions and complications will be helpful in future studies for better understanding of DOAC therapy-associated bleeding complications.

\section{Conclusion}

Laboratory tests may be useful in the assessment and prediction of bleeding risk in patients receiving DOAC therapy. Both PT and PTT prolonged at the same time had high association with bleeding, especially in patients receiving dabigatran or rivaroxaban. Impaired renal and liver functions had strong and moderate correlation, respectively, with DOAC therapy-associated bleeding complications in this study. Thrombocytopenia showed no significant difference between bleeding and non-bleeding patients. It is important to incorporate both laboratory findings and clinical information, such as concomitant antithrombotic agents and other underlying diseases, in the decision making of DOAC therapy in order to reduce therapy-related bleeding risk. 


\section{References}

[1] Bacchus, F. and Schulman, S. (2015) Clinical Experience with the New Oral Anticoagulants for Treatment of Venous Thromboembolism. Arteriosclerosis, Thrombosis, and Vascular Biology, 35, 513-519.

[2] Yao, X., Abraham, N.S., Sangaralingham, L.R., Bellolio, M.F., McBane, R.D., Shah, N.D. and Noseworthy, P.A. (2016) Effectiveness and Safety of Dabigatran, Rivaroxaban, and Apixaban versus Warfarin in Nonvalvular Atrial Fibrillation. Journal of the American Heart Association, 5, e003725.

[3] Gehrie, E. and Tormey, C. (2015) Novel Oral Anticoagulants: Efficacy, Laboratory Measurement, and Approaches to Emergent Reversal. Archives of Pathology \& Laboratory Medicine, 139, 687-692. https://doi.org/10.5858/arpa.2013-0677-RS

[4] Riva, N. and Ageno, W. (2015) Pros and Cons of Vitamin K Antagonists and Non-Vitamin K Antagonist Oral Anticoagulants. Seminars in Thrombosis and Hemostasis, 41, 178-187. https://doi.org/10.1055/s-0035-1544231

[5] Ebright, J. and Mousa, S.A. (2015) Oral Anticoagulants and Status of Antidotes for the Reversal of Bleeding Risk. Clinical and Applied Thrombosis/Hemostasis, 21, 105-114. https://doi.org/10.1177/1076029614545211

[6] Ufer, M. (2010) Comparative Efficacy and Safety of the Novel Oral Anticoagulants Dabigatran, Rivaroxaban, and Apixaban in Preclinical and Clinical Development. Seminars in Thrombosis and Hemostasis, 103, 572-585. https://doi.org/10.1160/TH09-09-0659

[7] Ruff, C.T., Giugliano, R.P., Braunwald, E., et al. (2014) Comparison of the Efficacy and Safety of New Oral Anticoagulants with Warfarin in Patients with Atrial Fibrillation: A Meta-Analysis of Randomized Trials. The Lancet, 383, 955-962. https://doi.org/10.1016/S0140-6736(13)62343-0

[8] Wallis, C.J.D., Juvet, T., Lee, Y., Matta, R., Herschorn, S., Kodama, R., Kulkarni, G.S., Satkunasivam, R., Geerts, W., McLeod, A., Narod, S.A. and Nam, R.K. (2017) Association between Use of Antithrombotic Medication and Hematuria-Related Complications. JAMA, 318, 1260-1271. https://doi.org/10.1001/jama.2017.13890

[9] Edupuganti, S., Xie, C., Wyrzykowski, M., Wey, E. and Xie, M. (2017) Bleeding Complications in Patients Receiving Direct Oral Anticoagulant Therapy in the Post Clinical Trial General Practice. American Journal of Clinical and Experimental Medicine, 5, 64-68. https://doi.org/10.11648/j.ajcem.20170503.12

[10] Mantha, S. and Ansell, J. (2015) Indirect Comparison of Dabigatran, Rivaroxaban, Apixaban and Edoxaban for the Treatment of Acute Venous Thromboembolism. Journal of Thrombosis and Thrombolysis, 39, 155-165. https://doi.org/10.1007/s11239-014-1102-5

[11] Pistersr, R., van Vugt, S.P.G., Brouwer, M.A., Elvan, A., ten Holt, W.L., Zwart, P.A.G., Kirchhof, P., Crijns, H.J.G.M. and Hemels, M.E.W. (2017) Real-Life Use of Rivaroxaban in the Netherlands: Data from the Xarelto for Prevention of Stroke in Patients with Atrial Fibrillation (XANTUS) Registry. Netherlands Heart Journal, 25, 551-558. https://doi.org/10.1007/s12471-017-1009-9

[12] Villines, T.C. and Peacock, W.F. (2016) Safety of Direct Oral Anticoagulants: Insights from Postmarketing Studies. American Journal of Medicine, 129, S41-S46. https://doi.org/10.1016/j.amjmed.2016.06.004

[13] Eikelboom, J. and Merli, G. (2016) Bleeding with Direct Oral Anticoagulants vs Warfarin: Clinical Experience. American Journal of Medicine, 129, S33-S40. https://doi.org/10.1016/j.amjmed.2016.06.003

[14] Noseworthy, P.A., Yao, X., Gersh, B.J., Hargraves, I., Shah, N.D. and Montori, V.M. 
(2017) Long-Term Stroke and Bleeding Risk in Patients with Atrial Fibrillation Treated with Oral Anticoagulants in Contemporary Practice: Providing Evidence for Shared Decision-Making. International Journal of Cardiology, 245, 174-177.

[15] Abraham, N.S., Singh, S., Alexander, G.C., Heien, H., Haas, L.R., Crown, W. and Shah, N.D. (2015) Comparative Risk of Gastrointestinal Bleeding with Dabigatran, Rivaroxaban, and Warfarin: Population Based Cohort Study. BMJ, 350, h1857. https://doi.org/10.1136/bmj.h1857

[16] Tran, H., Joseph, J., Young, L., McRae, S., Curnow, J., Nandurkar, H., Wood, P. and McLintock, C. (2014) New Oral Anticoagulants: A Practical Guide on Prescription, Laboratory Testing and Peri-Procedural/Bleeding Management. Australasian Society of Thrombosisand Haemostasis. Internal Medicine Journal, 44, 525-536. https://doi.org/10.1111/imj.12448

[17] January, C.T., Wann, L.S., Alpert, J.S., Calkins, H., Cigarroa, J.E., Conti, J.B., Ellinor, P.T., Ezekowitz, M.D., Field, M.E. and Murray, K.T. (2014) 2014 AHA/ACC/HRS Guideline for the Management of Patients with Atrial Fibrillation: A Report of the American College of Cardiology/American Heart Association Task Force on Practice Guidelines and the Heart Rhythm Society. Journal of the American College of Cardiology, 64, e1-e76. https://doi.org/10.1016/j.jacc.2014.03.022

[18] Burnett, A.E., Mahan, C.E., Vazquez, S.R., Oertel, L.B., Garcia, D.A. and Jack Ansell, J. (2016) Guidance for the Practical Management of the Direct Oral Anticoagulants (DOACs) in VTE Treatment. Journal of Thrombosis and Thrombolysiss, 41, 206-232. https://doi.org/10.1007/s11239-015-1310-7

[19] Biase, L.D. (2016) Use of Direct Oral Anticoagulants in Patients with Atrial Fibrillation and Valvular Heart Lesions. Journal of the American Heart Association, 5, e002776. https://doi.org/10.1161/JAHA.115.002776

[20] Kido, K. and Scalese, M.J. (2017) Management of Oral Anticoagulation Therapy after Gastrointestinal Bleeding: Whether to, When to, and How to Restart an Anticoagulation Therapy. Annals of Pharmacotherapy, 51, 1000-1007. https://doi.org/10.1177/1060028017717019

[21] Alotaibi, G., Alsaleh, K., Wu, C. and Mcmurtry, M.S. (2014) Dabigatran, Rivaroxaban and Apixaban for Extended Venous Thromboembolism Treatment: Network Meta-Analysis. International Angiology, 33, 301-308.

[22] Bashawri, L.A.M. and Ahmed, M.A. (2007) The Approach to a Patient with a Bleeding Disorder: For the Primary Care Physician. Journal of Family and Community Medicine, 14, 53-58.

[23] Neutze, D. and Roque, J. (2016) Clinical Evaluation of Bleeding and Bruising in Primary Care. American Family Physician Journal, 93, 279-286.

[24] Franchini, M., Bonfanti, C. and Mannucci, P.M. (2015) Management of Bleeding Associated with New Oral Anticoagulants. Seminars in Thrombosis and Hemostasis, 41, 788-801. https://doi.org/10.1055/s-0035-1556046

[25] Hellenbart, E.L., Faulkenberg, K.D. and Finks, S.W. (2017) Evaluation of Bleeding in Patients Receiving Direct Oral Anticoagulants. Vascular Health and Risk Management, 13, 325-342. https://doi.org/10.2147/VHRM.S121661

[26] Kirchhof, P., Benussi, S., Kotecha, D., et al. (2016) 2016 ESC Guidelines for the Management of Atrial Fibrillation Developed in Collaboration with EACTS. European Heart Journal, 37, 2893-2962. https://doi.org/10.1093/eurheartj/ehw210 